\title{
A PRÁTICA PSICOLÓGICA EM UMA MATERNIDADE HOSPITALAR: UM RELATO DE EXPERIÊNCIA
}

\author{
Luiza Moscato Soares ${ }^{1}$; Jessica Aguiar²; Giovana Farias Negrini; Júlia Katzer \\ Pedroso $^{4}$; André Luis Volmer ${ }^{5}$; Cristina Saling Kruel ${ }^{6}$
}

\section{RESUMO}

$\mathrm{Na}$ maternidade de um hospital de médio porte, a psicologia contém um olhar humanizado e direcionado principalmente para as demandas psicológicas emergentes da parturiente, puérpera e acompanhantes. Sendo esse um trabalho de grande importância para o suporte hospitalar. O objetivo deste trabalho consiste em relatar a experiência de um grupo de estagiárias de psicologia na maternidade de um hospital escola. $O$ trabalho trata-se de um relato de experiência que utiliza do método qualitativo. A partir da prática pode-se observar demandas como: planejamento familiar, histórico prévio de depressão, condutas do profissional psicólogo diante das situações problemas frente ao puerpério e interlocuções com a equipe multiprofissional. Conclui-se que a ação da equipe de psicologia além de estar ligada às demandas das mães usuárias do serviço de maternidade, volta-se também a família e a equipe. De forma a auxiliar na construção de um serviço mais humanizado.

Palavras-chave: Neonatal; Psicologia Hospitalar; Puerpério

Eixo Temático: Atenção Integral e Promoção à Saúde (AIPS).

\section{INTRODUÇÃO}

O nascimento de uma criança é um momento único para cada família, existem expectativas, fantasias e desejos em torno desse evento, o qual pode ser marcado por emoções positivas, mas também por medos e inseguranças. No entanto, independente da maneira como se desenrolar o processo de gravidez, parto

\footnotetext{
${ }^{1}$ Acadêmica do curso de Psicologia - UFN. moscato.luiza@ufn.edu.br

${ }^{2}$ Acadêmica do curso de Psicologia - UFN. jessica.aguiar@ufn.edu.br

${ }^{3}$ Acadêmica do curso de Psicologia - UFN. g.negrini@ufn.edu.br

${ }^{4}$ Acadêmica do curso de Psicologia - UFN. julia.kpedroso@ufn.edu.br

${ }^{5}$ Co-orientador. Psicólogo hospitalar do Hospital Casa de Saúde - HCS. andreluisvolmer@gmail.com

${ }^{6}$ Orientadora. Professora do curso de Psicologia - UFN. cristinakruel@ufn.edu.br
} 
e puerpério, se o seu andamento ocorreu como o planejado ou tiveram dificuldades inesperadas, o que deve ser garantido é o apoio e acolhimento pela equipe de saúde, tanto à mulher que carrega a criança quanto à sua família. Uma vez que o parto surge como o ultimato, o símbolo definitivo da passagem, o nascimento da criança e o renascimento da mulher (ALVES et al. 2011).

Seguindo esse entendimento, as instituições públicas responsáveis pelo atendimento das gestantes, parturientes e puérperas têm de disponibilizar um ambiente seguro a essas mulheres. Uma vez que a equipe multiprofissional, ao dirigir seus cuidados à paciente, torna-se parte da rede de segurança dela em uma circunstância de grande fragilidade. Lembrando do fato que a gestação ocasiona ressignificações na vida dos pais o que pode resultar em angústia, além das ansiedades desencadeadas pelo processo de nascimento ao se adentrar no serviço (SANTOS et al, 2011). Em razão disso, há a necessidade de um espaço direcionado à escuta psicológica proporcionada pelos psicólogos no hospital. O atendimento contribui para o processo de elaboração da gestação, nascimento, parto e futuro, também, podendo auxiliar no vínculo mãe-bebê como a aceitação do bebê real e com informações sobre a depressão pós parto (SANTOS et al, 2011).

Frente a questões como estas podemos compreender a relevância da psicologia nos serviços de saúde. Uma vez que os atendimentos psicológicos se propõem a auxiliar na fluidez da comunicação entre paciente-equipe-família, como uma tentativa de diminuir os processos de sofrimentos ocasionados por ruídos nas trocas de informação, trazendo um olhar técnico e humanizado para dentro do serviço (AZEVEDO et al, 2020).

No entanto, ainda que se entenda a importância do serviço de psicologia, o psicólogo enfrenta diversos obstáculos no desempenho da sua atuação. Esses estão relacionados a limitações do espaço, como os atendimentos realizados nos leitos, que muitas vezes são compartilhados. Tal fato acaba prejudicando a privacidade e o sigilo dos pacientes, podendo criar resistências na construção da fala dos usuários (QUEIROZ, 2020). 
Questões como essas são abordadas cotidianamente nos corredores dos serviços de maternidade, as quais foram exploradas durante a realização do estágio dentro de um Hospital de médio porte, através do curso de psicologia da Universidade Franciscana/UFN. Sendo assim, o objetivo deste trabalho consiste em relatar a experiência de um grupo de estagiárias de psicologia na maternidade de um hospital escola. Tal relato possui relevância ao trazer em pauta alguns aspectos de como se dá os serviços de psicologia dentro da unidade de maternidade. De forma a apoiar a prática profissional e informar acerca de temas que atravessam o serviço como: depressão pós-parto, condutas do profissional psicólogo diante das situações problemas frente ao puerpério, interlocuções com a equipe multiprofissional e planejamento familiar.

\section{METODOLOGIA}

Trata-se de um relato de experiência, constituindo-se assim em um estudo qualitativo pois não é possível quantificar os dados, buscando-se assim uma maior compreensão do contexto estudado. Considerando assim, a singularidade dos sujeitos envolvidos, a partir do entendimento da sua história e demandas (MINAYO, 2012).

O relato de experiência foi elaborado por um grupo de quatro acadêmicas do curso de Psicologia de uma universidade de ensino privado no interior do Rio Grande do Sul, Brasil. A prática do estágio que motivou o relato ocorreu em um hospital escola no período de abril a setembro de 2021. Entre as atividades realizadas, destaca-se o atendimento e acolhimento de gestantes, puérperas e acompanhantes na maternidade do hospital.

Como ferramenta de pesquisa utilizou-se o processo reflexivo diante da prática realizada no hospital. A partir da reflexão crítica buscou-se referencial bibliográfico, por meio de artigos e livros, que discutisse com os temas pertinentes percebidos durante a prática do estágio. 


\section{RESULTADOS E DISCUSSÕES}

O serviço de maternidade possui como participantes: as pacientes; as famílias; a equipe de saúde. O psicólogo é um dos profissionais que integra essa equipe multiprofissional, com um olhar humanizado e direcionado principalmente para as demandas psicológicas emergentes. Segundo Arrais e Mourão (2013) nesse contexto o psicólogo tem a função de compreender quais são as implicações do processo do parto para a mulher e para auxiliar ela e sua família em casos de complicações e intercorrências. Além disso, o profissional da psicologia ao trabalhar com a equipe de saúde busca opções para tornar as intervenções mais humanas e acessíveis.

Dentro do serviço, a relação com a equipe é refletida principalmente por meio da comunicação, a ferramenta fundamental para manter o ambiente hospitalar acolhedor para todos, porém, isso nem sempre se dá de forma efetiva. Dessa forma, a psicologia busca realizar práticas interventivas com a equipe de saúde, em que o psicólogo entra como mediador de processos atentando para os aspectos afetivos/emocionais, cognitivos e comportamentais, além da questão biomédica e das questões sociais atreladas a situação (HUTZ et al, 2019).

A falta de um olhar empático por parte da equipe pode gerar desestabilidade na paciente devido as desproporções sentidas diante do "saber médico". Sendo assim, o cuidado até mesmo com um vocabulário apropriado para a escolaridade da parturiente torna-se importante, ela está ali para experienciar o nascimento de seu filho. Ter atenção a essas especificidades na hora do trato com a paciente são decisivos para transformar o atendimento em uma troca acolhedora e efetiva, um cuidado que a psicologia costuma estar atenta. De forma a auxiliar durante as trocas ao enxergar os agentes desse processo situados dentro de suas subjetividades, como sujeito psicossociais, e não apenas como meros papéis dentro da trama institucional (AZEVEDO, 2020).

Quanto às questões específicas ligadas às mudanças ocorridas no psiquismo da paciente, verifica-se que o momento do pós-parto é marcado por uma avalanche 
de afetos unida às alterações hormonais que tornam o puerpério um período marcado por instabilidades emocionais. O chamado "Baby Blues" é uma consequência natural a esse momento de transições, o aparecimento de um humor depressivo diante da intensa elaboração psíquica que a troca de posição social carrega "a transformação da filha em mãe, a transformação da auto-imagem corporal e a relação entre sexualidade e a maternidade" (IACONELLI, 2005, p 32). Dentro da maternidade, a equipe de psicologia busca informar as puérperas acerca das características advindas desse estado e do possível rebaixamento do humor. Ainda, atentar quanto a importância de se manter uma rede de apoio fortalecida e possíveis encaminhamentos caso os sintomas se intensifiquem.

Diferente do Baby Blues, a depressão pós-parto é um quadro patológico que acomete tanto mulheres quanto homens, o qual pode colocar os pais e o bebê em uma posição de perigo. Essa possui causas subjetivas relacionadas a fatores de risco, as quais podem ser geradas pela sequência de mudanças que a chegada de um filho proporciona. Quando unida ao tabu cultural da dissociação entre sofrimento e parentalidade nos anos iniciais, ocasiona uma barreira na busca de informações e ajuda, pondo em risco a saúde mental de todos os envolvidos (IACONELLI, 2005). O atendimento psicológico breve oferecido às puérperas não tem recursos suficientes para garantir um diagnóstico, em decorrência do tempo de internação, o processo de trabalho de parto, nascimento e alta, ocorrem de forma muito dinâmica, geralmente dentro de 24 horas ou 48 horas. A equipe de psicologia busca realizar um acolhimento inicial, estar atenta a sinais ligados à vinculação entre mãe/bebê e o histórico da paciente, sugerindo encaminhamento à rede territorial, esse processo é chamado de contrarreferenciamento. Dessa forma, o psicólogo da rede estará habilitado para detectar fatores de risco para a ocorrência de uma depressão pós-parto, mediante um acompanhamento psicoterápico, a fim de auxiliar as gestantes a elaborar conflitos internos presentes na relação com a maternidade, com a criança que irá nascer, podendo minimizar os fatores depressivos que poderão aparecer no puerpério (CFP, 2019). 
Outro tema que atravessa os serviços de maternidade é o planejamento familiar. Tendo em vista a importância do exercício parental e da grande demanda que ele produz, compreende-se que o planejamento familiar se torna fundamental para o desenvolvimento saudável das relações na família. Uma vez que é um recurso o qual possibilita o direito de escolher de forma responsável a inclusão de outras pessoas no seu projeto de vida, conforme seus desejos e condições (DANTAS, 2018). Nesse tocante, notamos no serviço um índice considerável de casos de gravidez não planejada, principalmente, durante o período da adolescência. Gurgel et. al (2008) pontua que a não utilização de métodos contraceptivos ou o uso inadequado dos mesmos são comuns na fala dos adolescentes por motivos multifatoriais, entre eles, a desinformação ou a inserção em contextos de vulnerabilidade. Algo que se torna evidente é que a gravidez na adolescência é recebida de forma diferente em cada caso, podendo ser entendida como um fator de risco, mas por vezes como de proteção. Se enxergarmos a parentalidade como uma troca de interações entre os pais e os filhos que ocorre no contexto familiar e se baseia no comportamento dos mesmos junto às crianças, visando o desenvolvimento delas (CARVALHO et al, 2019). A imaturidade psíquica comum à adolescência pode revelar uma parentalidade que não alcança de forma suficiente às necessidades da criança. No entanto, em situações de vulnerabilidade, a gravidez pode significar uma ascensão à vida adulta ao proporcionar novas possibilidades de fazer social (SANTOS, et al 2010).

\section{CONCLUSÃO}

O principal objetivo de entrada no serviço de maternidade é o parto, um momento naturalmente repleto de afetividades e inseguranças. A comparação do bebê fantasiado e o bebê real, a troca do lugar de filha para o de mãe, a retomada da própria infância, "apenas" um universo inteiro de novas possibilidades para serem assimiladas num intervalo relativamente curto de tempo. E o parto surge como o ultimato, o símbolo definitivo da passagem, o nascimento da criança e o renascimento da mulher. Mais uma vez, a necessidade de um olhar além da 
dimensão física frente a um momento coberto de simbolismos. Dessa forma, buscar compreender as dificuldades que podem ser geradas pelo estado de sensibilidade que a parturiente está vivenciando faz parte de um atendimento humanizado, o qual o estágio em psicologia no hospital preza.

Também, tendo em vista, a alta taxa de gestações não planejadas, principalmente de adolescentes, é plausível a realização de intervenções da equipe de saúde com as puérperas em relação ao planejamento familiar e formas de controle de natalidade. Igualmente, sugere-se ações interventivas junto a equipe de saúde visando o aprimoramento do olhar empático para com os pacientes e a comunicação mais clara e efetiva entre os profissionais da maternidade.

\section{REFERÊNCIAS}

ARPINI M. D. et al. Conversando sobre planejamento familiar. 1. ed. Santa Maria: 2018. UFSM, CCSH, Departamento de Psicologia. Disponível em: https://www.ufsm.br/app/uploads/sites/518/2020/08/Cartilha-Planejamento-Familiar.p df. Acesso em: 09/04/2021.

AZEVEDO A. P. B. et al. A psicologia na maternidade hospitalar: um relato de experiência. Disponível em: https://www.scielo.br/scielo.php?script=sci_arttext\&pid=S1984-02922020000100057. Acesso em: 09/04/2021.

CARVALHO, O. et al. O valor das práticas de educação parental: visão dos profissionais. Disponível em http://www.scielo.br/scielo.php?script=sci_arttext\&pid=S0104-40362019000300654\&l ng=en\&nrm=iso. Acesso em: 17/09/2021. 
CONSELHO FEDERAL DE PSICOLOGIA (Brasil). Referências técnicas para atuação de psicólogas(os) nos serviços hospitalares do SUS / Conselho Federal de Psicologia, Conselhos Regionais de Psicologia e Centro de Referência Técnica em Psicologia e Políticas Públicas. — 1. ed. —— Brasília : CFP, 2019.

GURGEL, M. G. I. et. al. Gravidez na adolescência: tendência na produção científica de enfermagem. Disponível em: https://www.scielo.br/j/ean/a/qv5FGy98M9cPMSYRZM49TnC/?lang=pt\&format=pdf. Acesso em: 28/09/2021.

HUTZ, C. S. et al. Avaliação psicológica nos contextos de saúde e hospitalar. 1. ed. Porto Alegre: Artmed, 2019.

IACONELLI, V. Depressão pós-parto, psicose pós-parto e tristeza materna. Disponível em: https://www.nescon.medicina.ufmg.br/biblioteca/imagem/1927.pdf. Acesso em :09/09/21

MINAYO, M. C. S. Análise qualitativa: teoria, passos e fidedignidade. Ciência \& Saúde Coletiva, v. 17, n. 3, p. 621-626, 2012. Disponível em:

QUEIROZ, L. L. G. et al. A psicologia na maternidade hospitalar: um relato de experiência. Disponível em: https://doi.org/10.22409/1984-0292/v32i1/5679. Acesso em: 17/09/ 2021.

SANTOS, A. P. et al. A importância da psicologia no atendimento de mães e pais na maternidade. Disponível em:https://www.unisc.br/anais/jornada_pesquisa_psicologia/2011/arquivos/02.pdf. Acesso em: 16/09/ 2021. 
SANTOS, E, C. et al. Gravidez na adolescência: análise contextual de risco e proteção.

Disponível

em:

https://www.scielo.br/j/pe/a/BqKFcS478sbjFTnK3CypB6P/?format=pdf\&lang=pt. Acesso em: 28/09/2021.

WEBER, L. N. D. et al . Identificação de estilos parentais: o ponto de vista dos pais e dos filhos. Disponível em http://www.scielo.br/scielo.php?script= sci_arttext \& pid=S0102-79722004000300005 \& Ing= en $\mathrm{nrm}=i$ so. Acesso em: 16/09/2021. 